Article

\title{
Cynoglossus semilaevis Rspo3 Regulates Embryo Development by Inhibiting the Wnt/ $\beta$-Catenin Signaling Pathway
}

\author{
Jingjing Niu ${ }^{1}$, Jian Guan ${ }^{1}{ }^{10}$, Rui $\mathrm{Li}^{1}{ }^{1}$, Xuemei $\mathrm{Li}^{1}$, Jieming Zhai ${ }^{2}$, Jie $\mathrm{Qi}^{1}$ and Yan $\mathrm{He}^{1, *}$ \\ 1 Key Laboratory of Marine Genetics and Breeding, Ocean University of China, Ministry of Education, \\ Qingdao 266003, Shandong, China; nyjouc123@163.com (J.N.); guanjian@stu.ouc.edu.cn (J.G.); \\ 17854252538@163.com (R.L.); xuemeili5750@163.com (X.L.); qijie@ouc.edu.cn (J.Q.) \\ 2 Laizhou Mingbo Aquatic CO., Ltd., Laizhou 261418, Shandong, China; justdo123@163.com \\ * Correspondence: yanhe@ouc.edu.cn; Tel.: +86-532-8203-1986
}

Received: 8 May 2018; Accepted: 26 June 2018; Published: 29 June 2018

check for updates

\begin{abstract}
Cynoglossus semilaevis is an important economic fish species and has long been cultivated in China. Since the completion of its genome and transcriptome sequencing, genes relating to C. semilaevis development have been extensively studied. $R$-spondin 3 (Rspo3) is a member of the $R$-spondin family. It plays an important role in biological processes such as vascular development and oncogenesis. In this study, we cloned and characterized the expression patterns and functions of C. semilaevis Rspo3. Initial structural and phylogenetic analyses revealed a unique FU3 domain that exists only in ray-finned fish RSPO3. Subsequent embryonic expression profile analysis showed elevating expression of Rspo3 from gastrulation to the formation of the eye lens, while, in tail bud embryos, Rspo3 expression was significantly high in the diencephalon and mesencephalon. The overexpression of C. semilaevis Rspo3 in Danio rerio embryos resulted in a shortened rostral-caudal axis, edema of the pericardial cavity, stubby yolk extension, and ecchymosis. Vascular anomalies were also observed, which is consistent with Rspo3 role in vascular development. Drug treatment and a dual-luciferase reporter assay confirmed the inhibitory role of C. semilaevis Rspo3 in D. rerio Wnt/ $\beta$-catenin signaling pathway. We further concluded that the FU2, FU3, and TSP1 domains regulate the maternal Wnt/ $\beta$-catenin signaling pathway, while the FU1 domain regulates the zygotic Wnt/ $\beta$-catenin signaling pathway. This study enriches Rspo3 research in non-model animals and serves as the basis for further research into the interactions between Rspo and the Wnt/ $\beta$-catenin signaling pathway.
\end{abstract}

Keywords: RT-PCR; epiboly; vascular development; cysteine-rich furin-like domain; tongue sole

\section{Introduction}

Cynoglossus semilaevis is one of the important economic fish species in China and has long been the subject of large-scale breeding projects. With the completion of its genome and transcriptome sequencing [1,2], C. semilaevis has undergone intensive studies mainly focusing on the molecular mechanisms of growth, sex determination, and immunity.

The R-spondin (Rspo) proteins are a family of secreted proteins that a share similar domain organization, with all four members characterized by a signal peptide at the N-terminus, followed by two or three furin-like cysteine-rich domains (FU), a thrombospondin-type 1 domain (TSP1), and a basic amino acid-rich C-terminal domain [3-5]. Rspo1-4 are involved in embryonic development, cell proliferation, and tumorigenesis by activating the canonical Wnt/ $\beta$-catenin pathway [6-8], and it has been demonstrated that the FU domains are responsible for such function [9]. 
Rspo3, the first known member of the Rspo family, was identified in a high-throughput sequencing study of a human fetal brain cDNA library [10] and was later studied in mouse [11-13], Xenopus laevis [14], Danio rerio [5], and other model species. RSPO3 plays a regulatory role by activating the Wnt/ $\beta$-catenin signaling pathway. Moreover, RSPO3 is capable of inducing the non-canonical Wnt/PCP pathway by binding syndecan $4(S d c 4)$ [15]. Though RSPO role as an agonist of the Wnt pathway has been widely recognized, there is also contradicting evidence showing that RSPO3 inhibits the Wnt/ $\beta$-catenin signaling pathway in zebrafish embryos [5].

The functional study of Rspo3 has mainly focused on its role in development. Rspo3 is prominently expressed in blood-forming organs, and its deficiency leads to lethal vessel remodeling defects in mouse embryos [16]. Rspo3 could also promote vascular development in X. laevis by upregulating the expression of VEGF through the activation of the Wnt/ $\beta$-catenin signaling pathway. Since inhibiting the Wnt/ $\beta$-catenin signaling pathway could strengthen hematopoiesis, Rspo3 plays a role in keeping a balance between angiogenesis and hematopoiesis [14]. Moreover, a recent research shows that Rspo3 is a crucial regulator of coronary artery formation in the developing heart [17]. Further research indicates that Rspo3 can also maintain adult vessels. Overexpression of Rspo3 tightens endothelium junctions and prevents vascular leakage, thereby mitigating the inflammatory events and associated tissue damage in a mouse model of mesenteric ischemia-reperfusion [18]. In addition, Rspo3 is implied in limb, heart, and liver development [19-21].

Recently, the role of Rspo3 in oncogenesis has also become a hotspot. Rspo3 was identified as a protooncogene in a high-throughput study of retrovirus-induced mutant screening [22]. Later, Rspo3 was found to be correlated to childhood leukemia, secondary thyroid carcinoma, and colon cancer $[23,24]$. In addition, a recent study indicates that endogenous Rspo 2 and Rspo3 chromosome rearrangements can initiate and maintain tumor development [25].

More potential biological functions of Rspo3 were recognized with the expansion of genome-wide association studies (GWAS). These studies suggest that Rspo3 is involved in skeletal development and maintenance [26-28], fat distribution and metabolism [29-31], and expression of quantitative trait loci for human telomerase [32].

To date, most studies of Rspo3 have been conducted in model organisms, but its role in non-model animals such as $C$. semilaevis has been poorly studied. In this research, we characterized the temporal and spatial expression profiles of Rspo3 in the developmental stages of $C$. semilaevis and studied its function by overexpressing $C$. semilaevis Rspo3 mRNA in zebrafish embryos. Furthermore, we studied the effect of $C$. semilaevis Rspo3 on the Wnt/ $\beta$-catenin signaling pathway and explored the functions of different protein domains. This research is a detailed study of Rspo3 in non-model animals and provides insight for future $C$. semilaevis breeding.

\section{Results}

\subsection{Cloning and Sequence Structure Analysis}

We cloned the C. semilaevis Rspo3 gene by TA cloning and determined its gene structure by searching the NCBI database. C. semilaevis Rspo3 gene contains six exons and five introns (Figure 1A,B). A 993bp open reading frame (ORF) was obtained, which encodes a polypeptide comprised of 330 amino acids (Figure 1B). The polypeptide contains the typical domains of RSPO proteins, namely, a leading signal peptide at the N-terminus, three cysteine-rich furin-like domains (FU1, FU2, and FU3), a thrombospondin type I repeat domain (TSP1), and a coiled coil region (Co) at the C-terminus (Figure 1B). Especially, the FU3 domain is a unique structural feature, which is undetected in RSPO3 of mammals, birds, reptiles, amphibians, and even Chondrichthyes, as we found (Figure 2), as well as in other proteins of the $C$. semilaevis RSPO family. Furthermore, FU3 is closer to the FU2 domain in terms of sequence conservation and physicochemical properties. The FU1 domain has an additional segment peptide, which contains eight miscellaneous amino acids (Figure 1C). 


\subsection{Phylogenetic Analysis}

To elucidate the evolutionary history of the FU3 domain, a phylogenetic tree and a domain structure chart were constructed based on the amino acid sequences of RSPO3 from 35 species (Figure 2). Major vertebrate groups (cartilaginous fish, ray-finned fish, tetrapods) were roughly recovered, and this is supporting evidence for our correct ortholog identification. The phylogenetic analysis demonstrated that the RSPO3 orthologs of ray-finned fish were clustered into a clade, and those of tetrapods were clustered into another clade. All orthologs in the former clade have three FU domains, and all those in the latter clade have two FU domains. Ray-finned fish Rspo3 orthologs encode an additional FU domain (FU3) and display a faster evolutionary rate.

A

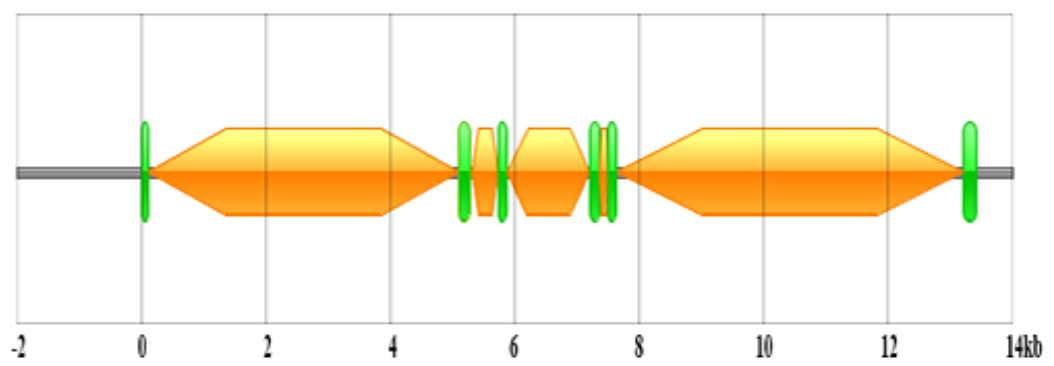

B
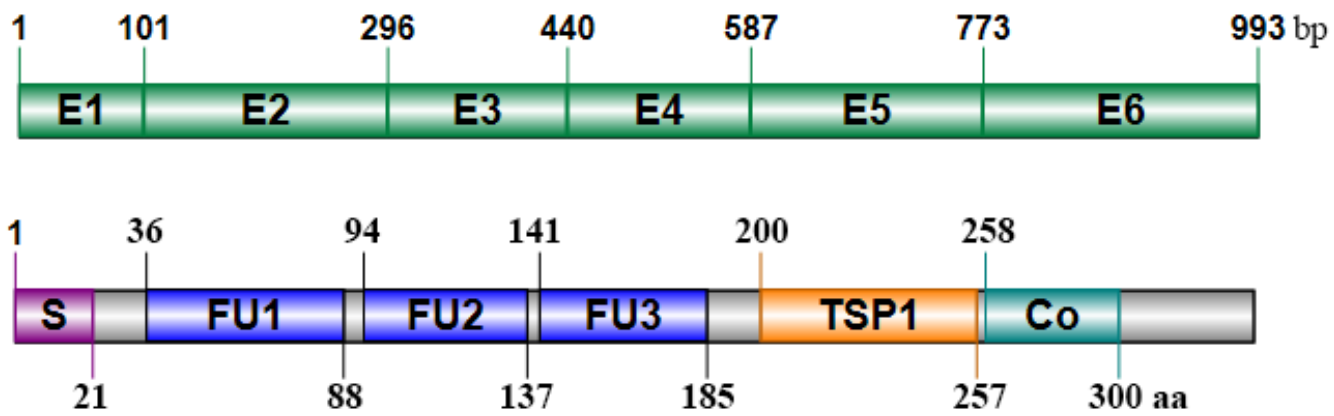

C

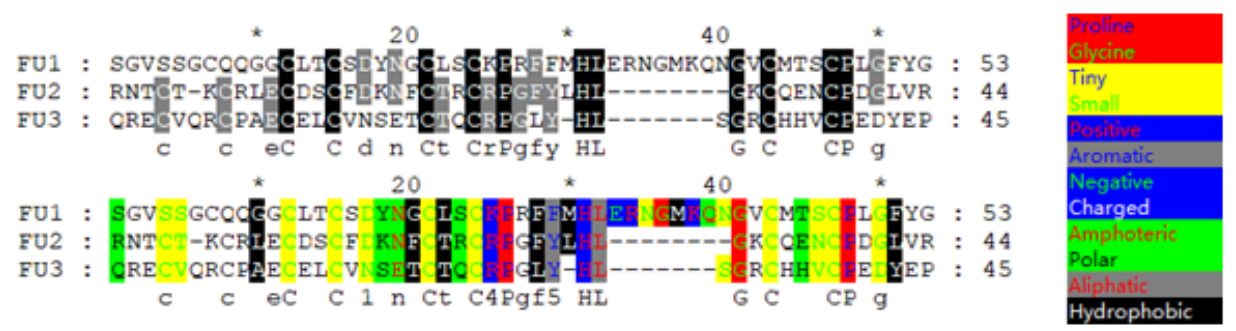

Figure 1. Sequence and structure of Cynoglossus semilaevis Rspo3/RSPO3. (A) Gene structure of Rspo3. Exons are shown in green quadrangles, whereas introns are shown in orange hexagons; (B) Above: exon composition of C. semilaevis Rspo3 coding sequences (CDS). Below: conserved domains of C. semilaevis RSPO3. E: exon; S: leading signal peptide; FU: cysteine-rich furin-like domain; TSP1: thrombospondin-type1 domain; Co: coiled coil region; (C) Sequence and physicochemical analysis of three FU domains. Above: amino acids that are conserved in the three domains are shown in black, whereas those that are conserved in two domains are shown in grey. Below: different physicochemical properties are marked in different colors. 

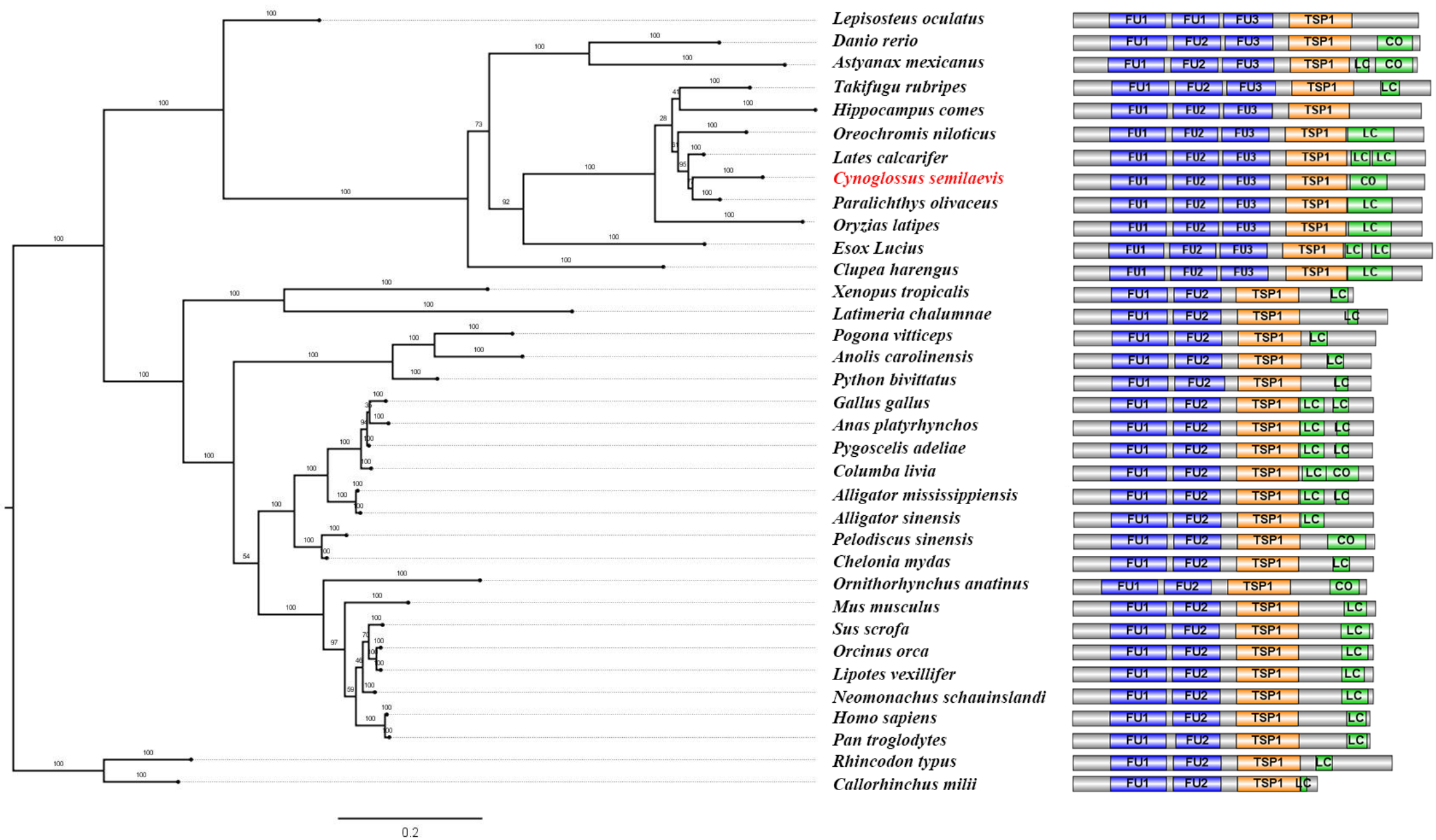

Figure 2. Phylogenetic and protein structure analysis of $C$. semilaevis and other vertebrate Rspo3/RSPO3 orthologs. The phylogenetic tree was constructed by MrBayes software, the lengths of the branches represent genetic distances, and bootstrap percentages are shown as numbers on the branches. The accession numbers are shown in the methods section. The protein structure is shown following the corresponding phylogenetic branch. FU: cysteine-rich furin-like domain; TSP1: thrombospondin-type1 domain; LC: low compositional complexity; Co: coiled coil region. 


\subsection{Embryonic Expression Pattern}

RT-PCR analysis showed that C. semilaevis Rspo3 mRNA was weakly expressed in the early developmental stages before 50\%-epiboly and was highly expressed in the subsequent stages (Figure 3A). The amount of transcripts continued to rise from 50\%-epiboly to the formation of the eye lens and then dramatically declined in the muscle-effective phase, entering a downtrend thereafter. To investigate the spatial expression pattern of Rspo3 in C. semilaevis, whole-mount in situ hybridization (WISH) was carried out in tail bud-forming-stage embryos, and strong antisense signals were observed in the diencephalon, metencephalon, and dorsal stripe (Figure 3B).

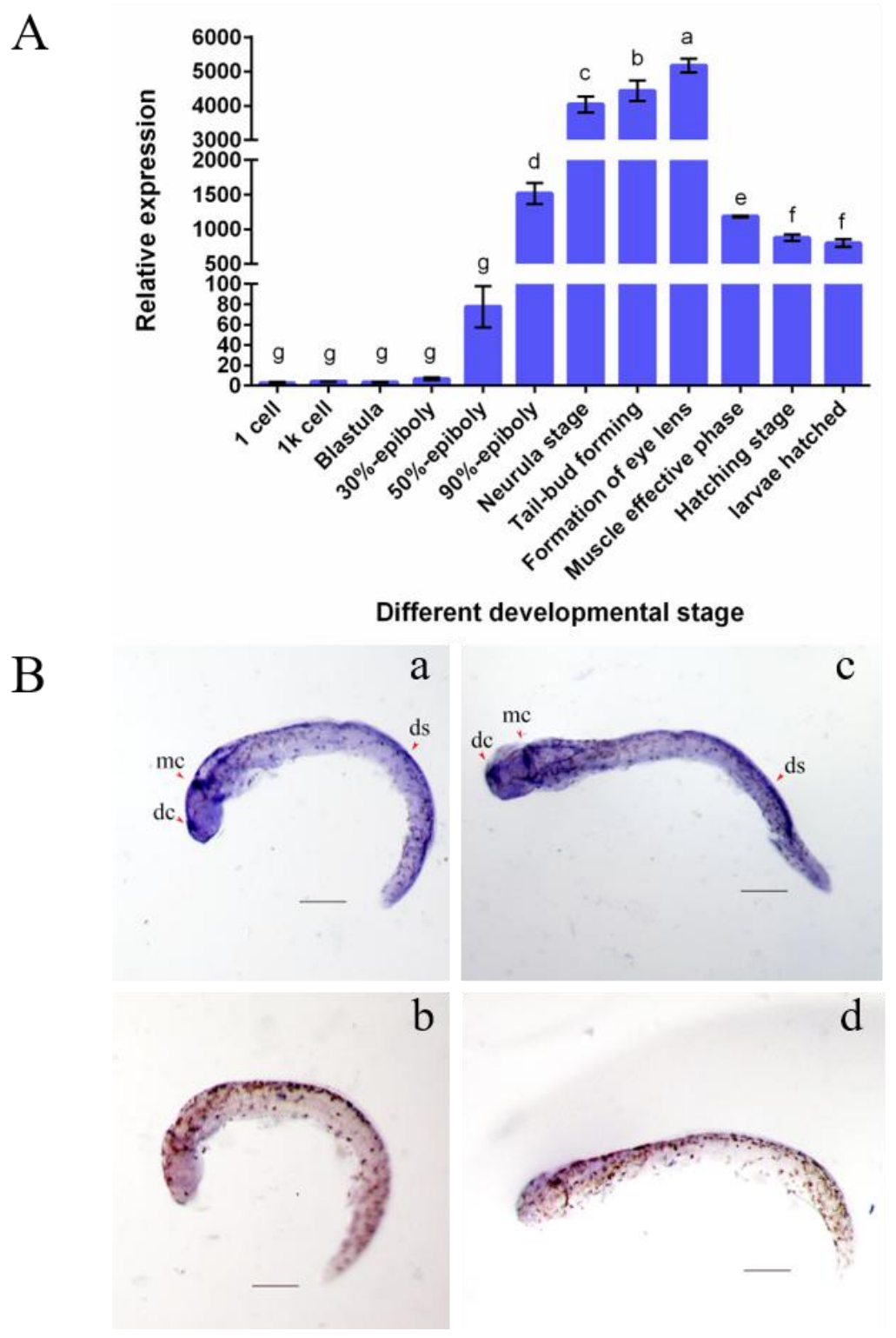

Figure 3. The spatiotemporal expression pattern of C. semilaevis Rspo3. (A) Expression profiles of Rspo3 mRNA at different embryonic developmental stages. B2M is the reference gene. The data are shown as mean \pm standard deviation (SD) (number of replicates, $n=3$; number of total samples analyzed in each group, $\mathrm{N}=90)$. Values with different superscripts indicate different statistical significance $(p<0.05)$; (B) Whole-mount in situ hybridization (WISH) analysis of Rspo3 mRNA at tail bud stage. The embryos are shown in lateral ( $a$ and b) and quarter (c and d) views, with anterior to the left. Scale bars $=200 \mu \mathrm{m}$; $\mathrm{a}$ and $\mathrm{c}$ correspond to anti-sense probes, $\mathrm{b}$ and $\mathrm{d}$ to sense probes. $\mathrm{dc}$ : diencephalon; mc: metencephalon; ds: dorsal stripe. 


\subsection{The Impact of C. semilaevis Rspo3 Overexpression on the Development of D. rerio Embryos}

To investigate its function in embryonic development, the capped mRNA of C. semilaevis Rspo3 was injected into D. rerio 1-4 cell embryos. The overexpression of C. semilaevis Rspo3 resulted in different degrees of malformation, with the phenotypic spectrum including shortened rostral-caudal axis, edema of the pericardial cavity, stubby yolk extension (Figure 4A,B), and ecchymosis in the pericardial cavity or the tail (Figure 4B). The deformation rate of $24 \mathrm{~h}$ post-fertilization (hpf) embryos was 33\%, and that of $54 \mathrm{hpf}$ embryos was $46 \%$ (Figure $4 \mathrm{C}$ ).

A

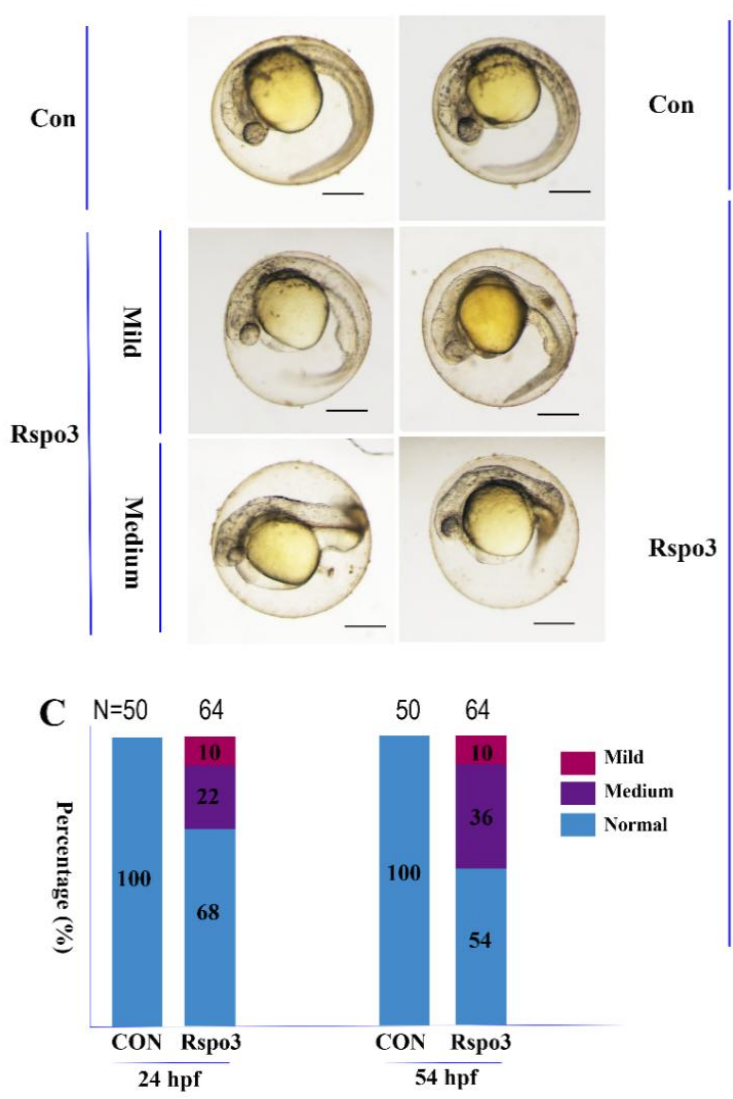

B

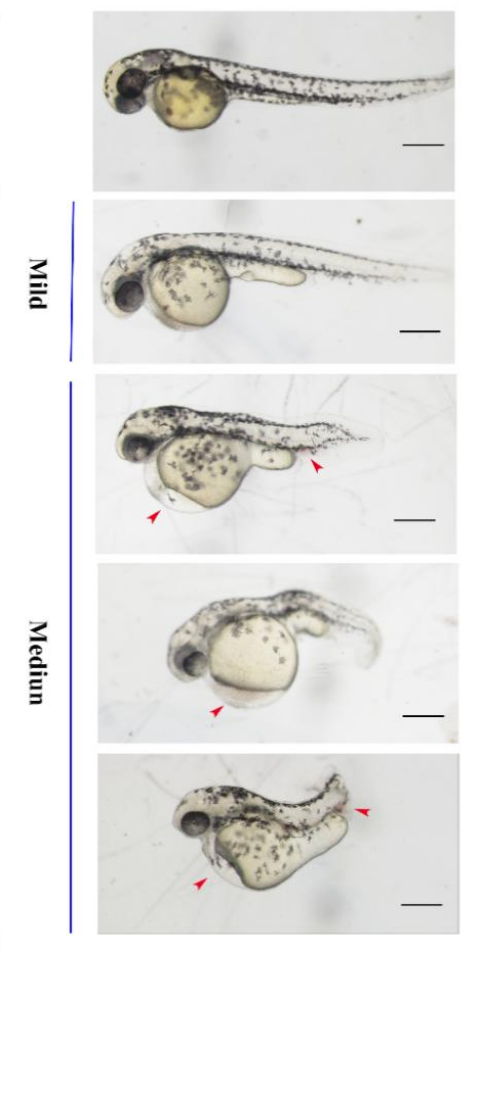

Figure 4. Overexpression of C. semilaevis Rspo3 affects Danio rerio embryo development. An amount of $1000 \mathrm{pg} / \mathrm{embryo}$ of C. semilaevis Rspo3 mRNA was injected into AB strain D. rerio embryos at 1-4 cell stages. All embryos are shown with anterior to the left. Scale bar $=200 \mu \mathrm{m}$. (A) Classification of phenotypes at $24 \mathrm{~h}$ post-fertilization (hpf); (B) Classification of phenotypes at $54 \mathrm{hpf}$. The red arrowheads indicate ecchymosis; (C) The percentages of embryos in each category as shown in (A) and (B); $\mathrm{N}$ is the number of total samples analyzed in each group.

Ecchymosis suggests that vascular development might have been affected, which was further substantiated by the observation of vascular anomalies and of the downregulation of VEGFa expression in 50\%-epipoly embryos (Figure 5). Among all blood vessels, optic vein (OV), lateral dorsal aorta (LDA), common cardinal vein (CCV), intersegmental vessel (Se), caudal vein (CV), and caudal aorta (CA) were the most seriously affected by the overexpression of $C$. semilaevis Rspo3 in transgenic strain (flila:EGFP) zebrafish embryos, with anomalous and undifferentiated LDA, absent Se, chaotic CV and CA (Figure 5A). The expression of VEGFa was significantly downregulated in the presence of excess Rspo3 in 50\%-epiboly embryos but was not significantly affected in $24 \mathrm{hpf}$ embryos (Figure 5B). The developmental disorders indicated that gastrulation might have been disrupted in mRNA-injected zebrafish embryos. 
A
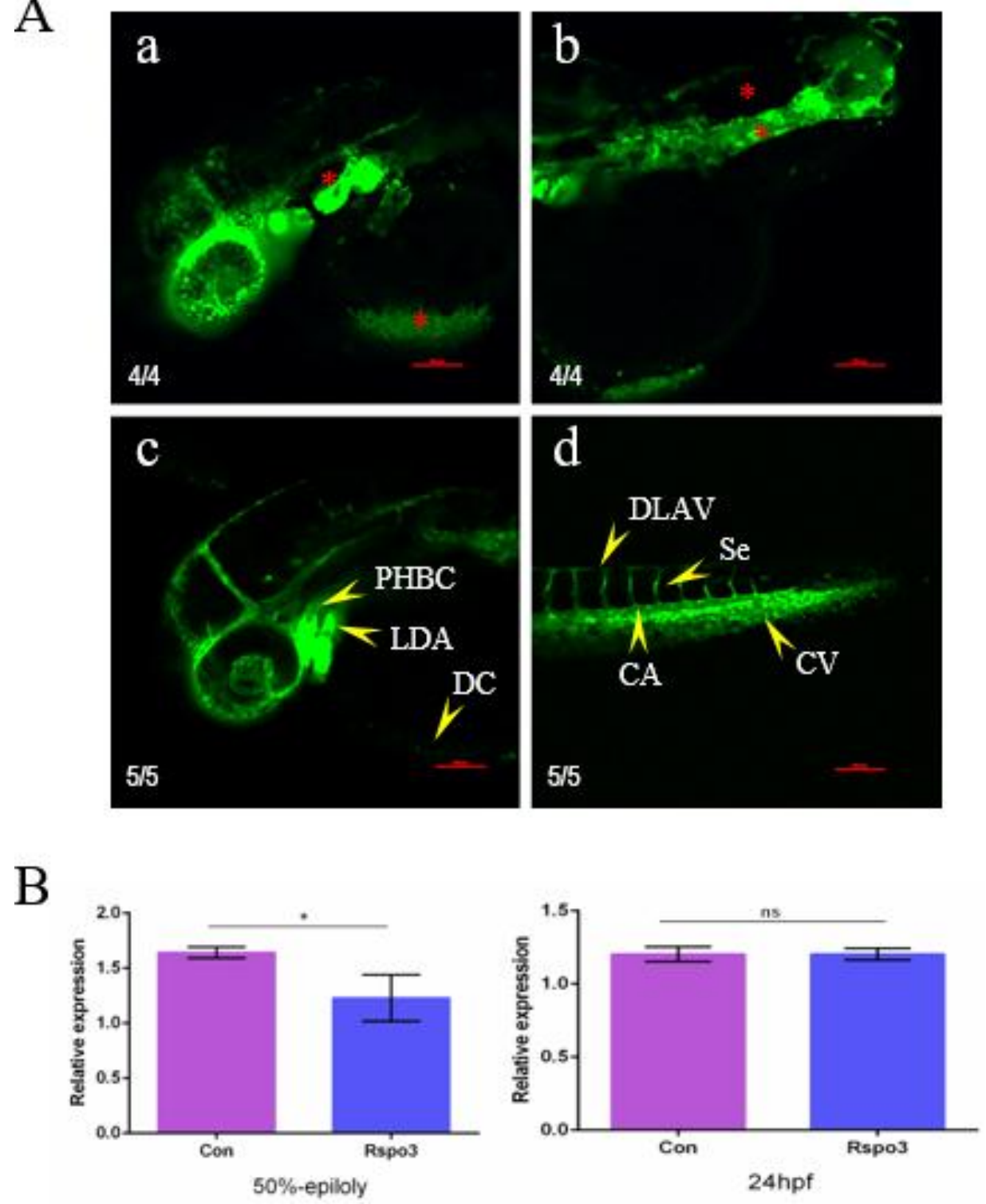

Figure 5. Overexpression of C. semilaevis Rspo3 affects angiogenesis in D. rerio embryos. (A) Vascular abnormalities induced by overexpression of $C$. semilaevis Rspo3 mRNA at $36 \mathrm{hpf}$; a and b show the most heavily impacted transgenic (flila: EGFP) strain D. rerio embryos. Each embryo was injected with 700 pg of C. semilaevis Rspo3 mRNA at 1-4 cell stages; c and d are the control group without injection. The yellow arrowheads indicate different types of vessels, whereas the red asterisks point out the abnormalities in the experimental group. All panels show the embryos oriented with anterior to the left. Scale bar $=100 \mu \mathrm{m}$. LDA: lateral dorsal aorta, CCV: common cardinal vein, Se: intersegmental vessel, CV: caudal vein, CA: caudal aorta; (B) Expression analysis of VEGFa at the 50\%-epiboly stage and $24 \mathrm{hpf}$. $\beta$-actin is the reference gene. The data are shown as mean $\pm \mathrm{SD}(n=3, \mathrm{~N}=30)$. Values with different superscripts or an asterisk indicate different statistical significance $\left({ }^{*} p<0.05 ; \mathrm{ns} p>0.05\right)$.

\subsection{C. semilaevis Rspo3 Plays a Role in Gastrulation by Regulating the Wnt/ $\beta$-Catenin Signaling Pathway}

We chose no tail ( $n t l)$, a marker gene of mesoderm, to assess the impact of $C$. semilaevis Rspo3 on the Wnt/ $\beta$-catenin signaling pathway and gastrulation. Three groups of zebrafish embryos were incubated with the Wnt/ $\beta$-catenin signaling pathway activator 6-bromoindirubin-3'-oxime (BIO) or with the inhibitor XAV-939 or were microinjected with capped C. semilaevis Rspo3 mRNA, and their $n t l$ expression levels were analyzed by RT-PCR and WISH. 
We observed that, in terms of $n t l$ expression patterns and phenotype, the mRNA-injected embryos were closer to XAV-939-treated embryos than to embryos treated with BIO. The overall expression of $n t l$ was significantly downregulated during the epiboly phase in both mRNA-injected and XAV-939-treated embryos but was upregulated in BIO-treated embryos (Figure 6D). Moreover, the expression of $n t l$ in both the mesoderm and the ectoderm increased after BIO treatment, while it decreased in the mesoderm of mRNA-injected or XAV-939-treated groups, especially in the ventral mesoderm (Figure 6C). The embryos of all three groups displayed a similar proportion of mild pericardial edema, whereas medium anomalies were much more prevalent in BIO-treated embryos (Figure 6B). Such similarities between C. semilaevis Rspo3 and XAV-939 indicate the possibility that the former regulates gastrulation by serving as an inhibitor of the zebrafish $W n t / \beta$-catenin signaling pathway.

A

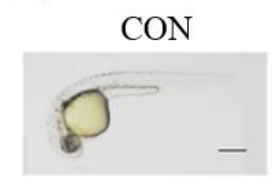

C $\mathrm{CON}$

a
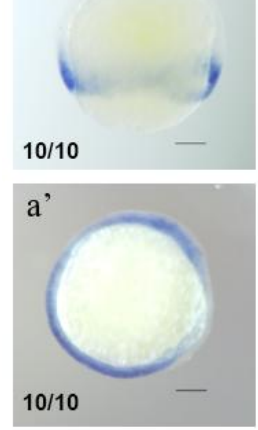

BIO

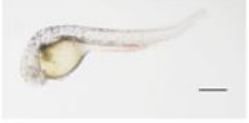

BIO
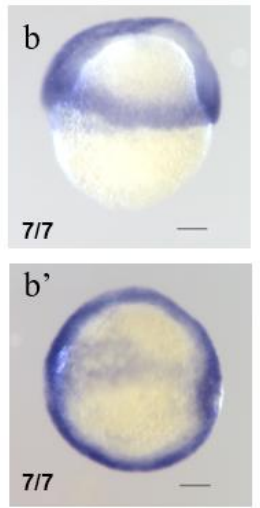

XAV-939

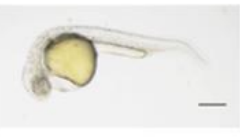

XAV-939
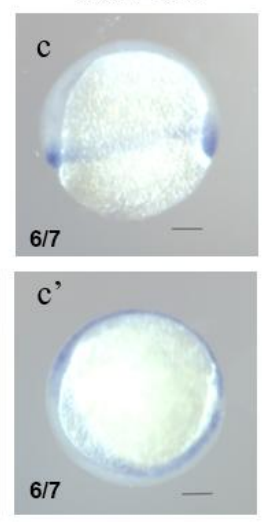

$\mathrm{B}$

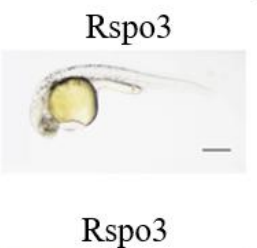

d
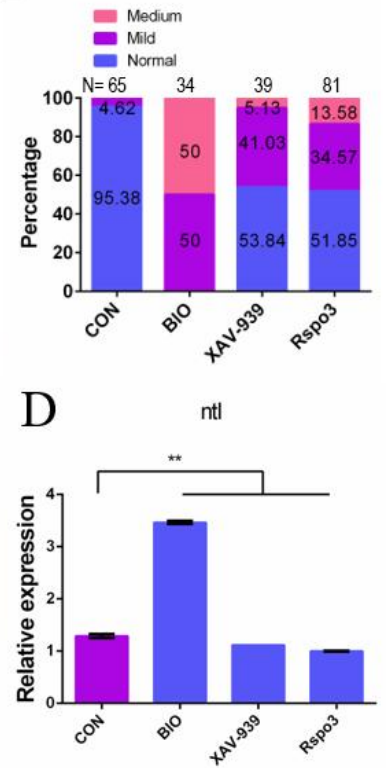

Figure 6. C. semilaevis Rspo3 affects mesoderm formation by regulating the Wnt/ $\beta$-catenin signaling pathway. (A) AB strain D. rerio $24 \mathrm{hpf}$ embryos after treatment with $0.15 \mu \mathrm{M}$ BIO or $1.67 \mu \mathrm{M}$ XAV-939, or microinjection with $1000 \mathrm{pg}$ C. semilaevis Rspo3 mRNA per embryo. All embryos are shown oriented with anterior to the left. Scale bar $=200 \mu \mathrm{m}$; (B) Abnormality rates of embryos in each group as shown in (A), $\mathrm{N}$ is the number of total samples analyzed in each group; (C) WISH analysis of $n+l$ at the gastrula stage in each group; $a-d$ are lateral views, whereas a' $-d^{\prime}$ are quarter views. Scale bar $=200 \mu \mathrm{m}$; (D) RT-PCR analysis of $n t l$ at the gastrula stage in each group. $\beta$-actin is the reference gene. The data are shown as mean $\pm \mathrm{SD}(n=3, \mathrm{~N}=30)$. The superscript indicates statistical significance $(* * p<0.01)$.

\subsection{C. semilaevis Rspo3 Suppresses the Wnt/B-Catenin Signaling Pathway in D. rerio Embryos}

A dual-luciferase reporter assay was carried out to further substantiate the role of Rspo3. Luciferase activity in embryos microinjected with C. semilaevis Rspo3 mRNA was significantly downregulated, while that in embryos microinjected with $D$. rerio Wnt3a mRNA was significantly upregulated (Figure 7A). Moreover, RT-PCR showed that the expression of $b o z$, a target gene of $D$. rerio maternal $\beta$-catenin, was significantly downregulated by overexpressing C. semilaevis Rspo3 mRNA but was significantly upregulated by BIO treatment. Unfortunately, WISH results were not as obvious as those of RT-PCR and only showed a slight change after mRNA injection. To understand the inhibitory role of C. semilaevis Rspo3 in the Wnt/ $\beta$-catenin pathway, we characterized the expression of ZNRF3, an RSPO receptor, in zebrafish embryos overexpressing Rspo3 and Wnt3a, respectively. We demonstrated that ZNRF3 expression was significantly upregulated after Rspo3 overexpression but did not show any changes after Wnt3a overexpression (Figure 7B). 

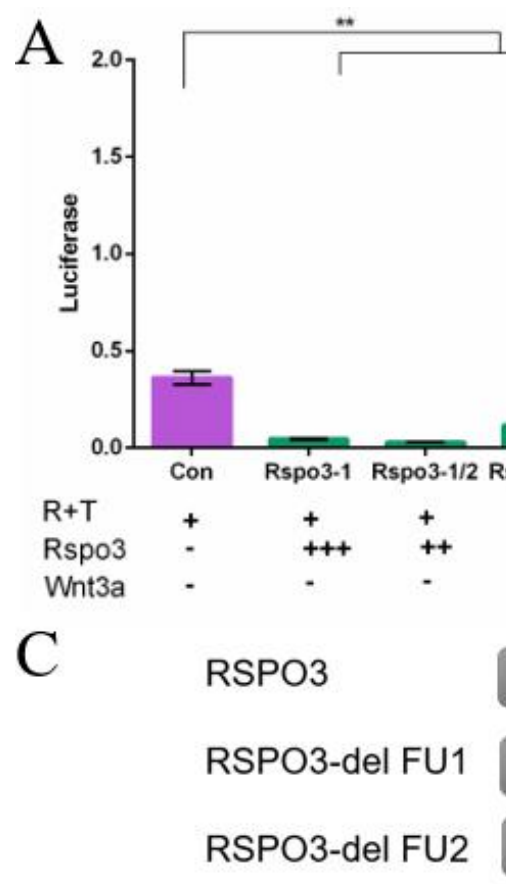

RSPO3-del Fu3

RSPO3-del TSP

$\mathrm{D}$

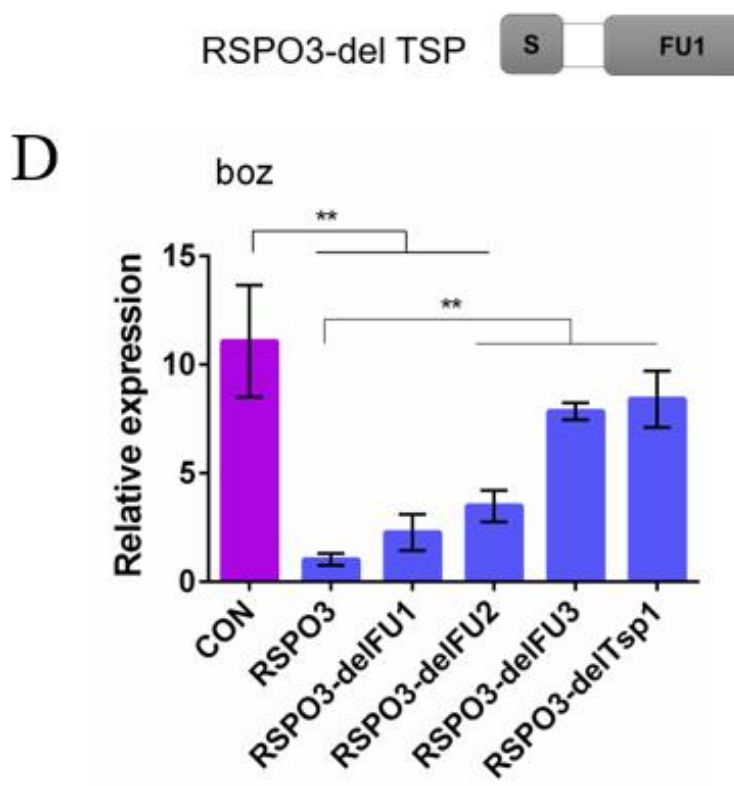

$\mathrm{B}$

ZNRF3

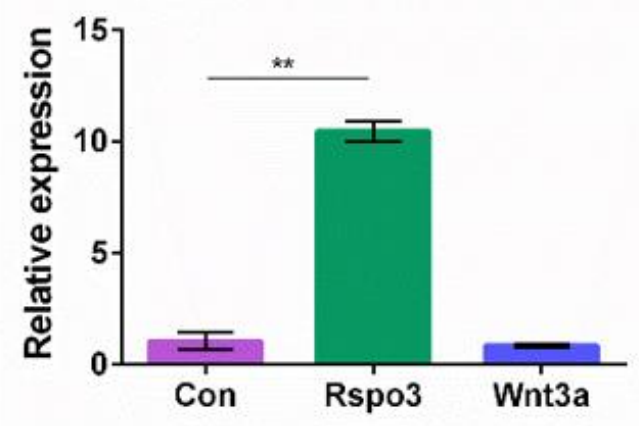

$\mathrm{E}$

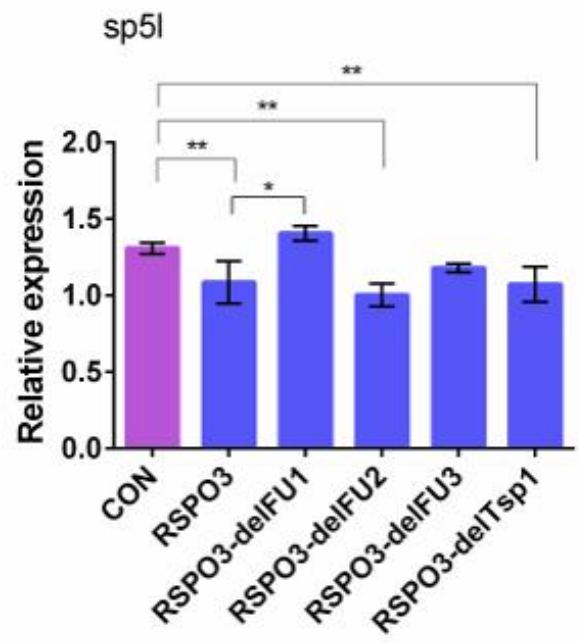

Figure 7. C. semilaevis Rspo3 inhibits the Wnt/ $\beta$-catenin signaling pathway in $D$. rerio embryos. (A) The dual-luciferase reporter assay shows that $C$. semilaevis Rspo3 inhibits Wnt/ $\beta$-catenin reporter activities. AB strain D. rerio embryos at 1-4cell stage were injected with $200 \mathrm{pg}$ TOPFlash plasmid and 40 pg Renilla plasmid together with 1400 pg, 700 pg, 350 pg C. semilaevis Rspo3 mRNA or 20 pg zebrafish Wnt3a mRNA each. $\beta$-actin is the reference gene. The data are shown as mean $\pm \operatorname{SD}(n=3$, $\mathrm{N}=90$ ). The superscripts indicate statistical significance $\left.{ }^{* *} p<0.01\right)$; (B) RT-PCR analysis of ZNRF3 at $50 \%$-epiboly stage. AB D. rerio embryos at $1-4$ cell stage were injected with $700 \mathrm{pg} C$. semilaevis Rspo3 mRNA or $20 \mathrm{pg} D$. rerio Wnt3a mRNA. The data are shown as mean $\pm \mathrm{SD}(n=3, \mathrm{~N}=30)$. The superscripts indicate statistical significance $(* * p<0.01)$; (C) The core structure composition of each domain-deleted RSPO3 plasmid. (D,E) RT-PCR analysis of $b o z$ and $s p 5 l$ at the 50\%-epiboly stage. $\mathrm{AB} D$. rerio embryos at the 1-4 cell stage were injected with $500 \mathrm{pg} C$. semilaevis Rspo3 mRNA or domain-deleted C. semilaevis Rspo3 mRNA. The data are shown as mean $\pm \mathrm{SD}(n=3, \mathrm{~N}=30)$. Values with different superscripts indicate different statistical significance $\left({ }^{*} p<0.05 ; * *<0.01\right)$. 
In order to study the roles of different $C$. semilaevis RSPO3 domains in regulating the Wnt/ $\beta$-catenin signaling pathway, four types of domain-deletion plasmids ( $\mathrm{P}^{R S P O 3-d e l F U 1}, \mathrm{P}^{R S P O 3}$-delFU2, $\mathrm{P}^{R S P O 3-d e l F U 3}$, $\mathrm{P}^{R S P O 3-\text { delTSP1}}$ ) were constructed by seamless cloning (Figure $7 \mathrm{C}$ ). Each one of the five groups of $50 \%$-epiboly $D$. rerio embryos were microinjected with one type of domain-deletion Rspo3 mRNA or wild-type Rspo3 mRNA. The samples were analyzed to detect the expression of the direct maternal $\beta$-catenin target gene $b o z$ and the zygotic Wnt/ $\beta$-catenin signaling target gene $s p 5 l[5,33]$. The expression of both $b o z$ and sp5l was significantly downregulated after injecting wild-type Rspo3 mRNA (Figure 7D,E). However, FU3- and TSP1-deleted Rspo3 mRNA failed to induce a significant decrease in boz expression, while, though both FU1- and FU2-deleted Rspo3 mRNA resulted in a significant downregulation of boz expression, only the former displayed no significant differences compared with the effects of the wild-type plasmid, indicating that only the FU1 domain is dispensable for inhibiting the maternal Wnt/ $\beta$-catenin signaling pathway. In comparison with $b o z$, the expression of sp5l was not significantly changed by FU1- and FU3-deleted Rspo3 mRNA, while only the former displayed a significant difference compared to that of the wild-type plasmid, indicating that it inhibited the zygotic Wnt/ $\beta$-catenin signaling pathway. Taken together, these results indicate that the FU1 domain is the major inhibitor of the zygotic Wnt/ $\beta$-catenin signaling pathway, while the other three domains are responsible for inhibiting the maternal Wnt/ $\beta$-catenin signaling pathway.

\section{Discussion}

In this study, we characterized the ORF sequence of C. semilaevis Rspo3, which is 993 bp long and encodes a peptide of 330 amino acids. Though most RSPO proteins contain only two FU domains, RSPO3 of $C$. semilaevis and other ray-finned fish species contain three FU domains [5]. A phylogenetic analysis also showed that Rspo3 genes with three FU domains have a faster evolutionary rate than those with two FU domains, and FU3 is closer to the FU2 domain compared with the FU1 domain in terms of sequence conservation and physicochemical properties.

The analysis of the embryo expression profiles showed elevating mRNA expression in C. semilaevis from the gastrula stage until the formation of the eye lens and a relatively low expression level thereafter. There was a significant elevation of Rspo3 expression from the 50\%-epiboly to the $90 \%$-epiboly stage, which coincides with the formation of three germ layers. The formation of three germ layers is one of the most important events during gastrulation and is critical to organ and tissue fate map determination [34]. This indicates that $C$. semilaevis Rspo3 might play a role in regulating the formation and patterning of the germ layers. The temporal expression pattern of C. semilaevis Rspo3 is analogous to that of $D$. rerio and is different from that of mouse and Xenopus. The expression of D. rerio Rspo3 mRNA was initially detected in fertilized eggs and remarkably increased at $9 \mathrm{hpf}(90 \%$-epiboly stage) [5]. In contrast, the expression of Rspo3 was initially detected at the gastrulation stage in Xenopus [6] and in the primitive streak at embryonic day 7.5 (E7.5) in mouse [13]. However, Rspo3 is expressed at a relative high level during gastrulation in all these species, which indicates that the role of Rspo3 as a regulator of gastrulation is highly conserved.

After gastrulation, the expression of C. semilaevis Rspo3 mRNA was detected in tail bud embryos. Positive signals were detected in the diencephalon and mesencephalon. The spatial expression patterns of Rspo3 displayed both similarities and differences among the aforementioned species. D. rerio Rspo3 displayed a tissue specific expression pattern after $12 \mathrm{hpf}$, with strong signals detected in brain (including telencephalon, diencephalon, metencephalon, rhomb-encephalon) and other tissues [5]. Mouse Rspo3 mRNA was detected in the posterior primitive streak and allantois at E8.0 and in the forebrain, dorsal neural tube, migrating neural crest cells, limb bud, and developmental heart from E9.0 to E10.5 [13,14,35]. X. laevis Rspo3 mRNA was detected in the neural plate at stage 17 and in the forebrain, branchial arches, pronephric sinus, dorsal neural tube, dorsal plate, ventral blood island, and tail-bud mesoderm at stage 28 [14]. The conservative expression of Rspo3 in the brain among these species suggests that Rspo3 is involved in the development of the central nervous system. Regrettably, we did not get more spatial expression information for $C$. semilaevis because only tail bud embryos were analyzed by WISH. 
Because of the infeasibility of microinjection in C. semilaevis embryos and considering the similarity of protein structure and expression patterns between C. semilaevis and D. rerio Rspo3, a gain-of-function analysis was conducted by overexpressing C. semilaevis Rspo3 mRNA in D. rerio embryos. The forced expression of Rspo3 caused phenotypic malformations in D. rerio, including a shorter axis, edema of the pericardial cavity, stubby yolk extension, and ecchymosis in the pericardial cavity or tail. Vascular anomalies were identified by fluorescence and indicated by the decreased of VEGFa in $50 \%$-epiboly embryos. The mechanisms of such abnormal development were studied by using molecular markers. Since gastrulation is regulated by the Wnt/ $\beta$-catenin signaling pathway, and previous studies have implied the involvement of Rspo3 in regulating the Wnt / $\beta$-catenin signaling pathway [3-5,9], we speculated that $C$. semilaevis Rspo3 could also interact with this pathway in zebrafish. The expression of $n t l$ in $D$. rerio was downregulated by overexpressing C. semilaevis Rspo3 or treating with XAV-939. This indicated that $C$. semilaevis Rspo3 regulates the formation and patterning of mesoderm via regulating the $\mathrm{Wnt} / \beta$-catenin signaling pathway.

Rspo3 expression is related to vasculogenesis and angiogenesis in both Xenopus and mouse. Xenopus Rspo3 is expressed in the dorsal lateral plate and ventral blood islands [14], while mouse Rspo3 is expressed in the posterior primitive streak, allantois, and blood vessels [14,35]. All these sites are related to vasculogenesis and angiogenesis. It was further confirmed that $R$ spo 3 regulates the balance between blood and endothelial differentiation by triggering Wnt/ $\beta$-catenin signaling to activate the immediate early target gene VEGF [14]. Consequently, the ecchymosis observed in the pericardial cavity or tail in seriously affected $D$. rerio embryos by overexpressing $C$. semilaevis Rspo3 may result from the downregulation of VEGFa. This speculation was substantiated by observations in transgenic strain (flila: EGFP) zebrafish embryos. Based on the above results, the abnormal phenotype and downregulation of VEGFa suggest that $C$. semilaevis Rspo3 inhibits the Wnt/ $\beta$-catenin signaling pathway.

Although previous research conducted in Xenopus and other vertebrates revealed an activatory role of Rspo in regulating the Wnt/ $\beta$-catenin signaling pathway $[4,9,12,36,37]$, there is also contradicting evidence showing that Rspo3 inhibits the Wnt/ $\beta$-catenin signaling pathway in $D$. rerio embryos [5]. We employed a dual-luciferase reporter assay to further substantiate our conclusions in C. semilaevis. Contrary to Wnt3a, Rspo3 significantly reduced TOPFlash reporter expression induced by endogenous Wnt/ $\beta$-catenin signaling pathway. In addition, the expression of the maternal $\beta$-catenin target gene boz and zygotic Wnt/ $\beta$-catenin signaling target gene sp $5 l$ were downregulated at $50 \%$-epiboly by overexpressing $C$. semilaevis Rspo3, supporting the conclusion that $C$. semilaevis Rspo3 inhibits the Wnt/ $\beta$-catenin signaling pathway. Taken together, our results suggest that $C$. semilaevis Rspo3 suppresses $W n t / \beta$-catenin signaling pathway in $D$. rerio.

In $D$. rerio embryos, maternal $\beta$-catenin accumulates in dorsal margin blastomeres and establishes dorsal patterning by activating the expression of $b o z$ after the mid-blastula transition, while zygotic $W n t / \beta$-catenin signaling is essential for the specification of the ventral and posterior fates $[33,38]$. Though the expression of boz is not affected significantly by overexpressing Rspo3 in D. rerio at the sphere stage [5], our study showed that it was downregulated at the $50 \%$-epiboly stage by overexpressing C. semilaevis Rspo3 in D. rerio embryos, which indicates that the zygotic Wnt/ $\beta$-catenin signaling pathway is functional at the $50 \%$-epiboly stage but not at the sphere stage. Regardless of the cause, the downregulation of $b o z$ and $s p 5 l$ indicates that C. semilaevis Rspo3 inhibits the Wnt/ $\beta$-catenin signaling pathway in zebrafish.

We studied the expression of ZNRF3, one of the RSPO receptors, in order to explore the mechanisms of the interaction between $C$. semilaevis Rspo3 and the Wnt/ $\beta$-catenin signaling pathway. LGR4-6 and ZNRF3/RNF43 have been identified as RSPO receptors [37,39-42]. LGR4-6 are G protein-coupled receptors with leucine-rich repeats, whose binding effects have been confirmed by a series of experiments $[37,39,40,43,44]$, and it has been shown that RSPO binds to LGR4- 6 via the FU domain [45]. However, a recent study discovered that RSPO2 and RSPO3 can activate the Wnt/ $\beta$-catenin signaling pathway in the absence of LGR4-6 [46]. ZNRF3 and RNF3, another type of 
RSPO receptors, are E3 ubiquitin-ligase enzymes that can downregulate the Wnt signaling pathway by promoting ubiquitination and degradation of Wnt receptors. It was found that RSPO, LGR4-6, ZNRF3, and RNF43 can form a ternary complex to eliminate the FZD-LRP complex from the membrane [41,42]. Our study shows that the expression of ZNRF3 in 50\%-epiboly zebrafish embryos was significantly upregulated by overexpressing $C$. semilaevis Rspo3. This provides a new perspective to understand the inhibitory role of $C$. semilaevis Rspo3 in regulating the Wnt/ $\beta$-catenin signaling pathway.

We further constructed different types of domain-deletion plasmids to explore the contribution of different domains regulating the Wnt/ $\beta$-catenin signaling pathway. The expression of boz and sp $5 l$ in 50\%-epiboly D. rerio embryos microinjected with the corresponding domain-deletion Rspo3 mRNA was detected. We concluded that the FU2, FU3, and TSP1 domains are important for regulating the maternal Wnt/ $\beta$-catenin signaling pathway, while the FU1 domain is important for regulating the zygotic Wnt/ $\beta$-catenin signaling pathway. It was reported that RSPO1-2 can bind to RNF3 and ZNRF3 via the FU1 domain and to LGR via the FU2 domain and that the ability of binding ZNRF3/RNF3 differs significantly among RSPO1-4 [47,48]. A recent research demonstrated that the heparin sulfate proteoglycans (HSPGs) were essential in LGR-independent signaling [46]. Our study showed that different domains contributed differently to the inhibition of the Wnt / / $\beta$-catenin signaling pathway, and C. semilaevis Rspo3 regulated the maternal and zygotic Wnt/ $\beta$-catenin signaling pathway depending on different domains.

However, the interactions between receptors and specific C. semilaevis Rspo3 domains need to be studied further. In addition, phylogenetic and physicochemical analyses showed that the FU3 domain is closer to the FU2 domain, while the FU1 domain has an extra peptide containing eight consecutive and miscellaneous amino acids. Whether the structural and physicochemical differences among the FU domains play a role in regulating interactions with other proteins also needs further study.

In conclusion, the expression and function of C. semilaevis Rspo3 were studied in this research. Our results enrich the study of Rspo3 in non-model animals and provide insight for C. semilaevis breeding.

\section{Methods}

\subsection{Samples}

C. semilaevis fish and embryos were collected from Laizhou Mingbo Aquatic Co., Ltd., in Yantai, China. Tissues and organs, including brain, gill, heart, intestine, kidney, liver, muscle, spleen, and gonads were collected from three one-year-old male and female individuals for RNA extraction. Adult tissues and embryos for RNA extraction were stored in RNAwait (Solarbio), and embryos for WISH were stored in $4 \%$ PFA.

Zebrafish, 1-1.5-year-old, (wild-type AB strain and transgenic strain (flila: EGFP)) were cultured under a $14 \mathrm{~h}$ light-10 h dark cycle. Embryos were obtained by natural crossing, kept in Holtfreter buffer at $28.5^{\circ} \mathrm{C}$, and staged according to standards proposed by Kimmel et al. [34] The samples for RNA extraction were frozen in liquid nitrogen and stored at $-80^{\circ} \mathrm{C}$.

All experimental protocols concerning animals were conducted in accordance with the regulations of the Ethical Committee of Experimental Animal Care, Ocean University of China (Permit Number: 11001).

\subsection{Total RNA Extraction and cDNA Synthesis}

Total RNA from adult tissues and embryos was extracted with Trizol Reagent (Invitrogen, Carlsbad, CA, USA) according to the manufacturer's protocol. Adult tissue cDNA synthesis was performed with Reverse Transcriptase M-MLV Kit (TaKaRa, Dalian, China), while embryo cDNA was synthesized by PrimeScript ${ }^{\mathrm{TM}}$ RT reagent Kit with gDNA Eraser (Perfect Real Time) (TaKaRa). cDNA purity and concentration were determined by $1.5 \%$ agarose gel electrophoresis and UV spectrophotometry using NanoPhotometer Pearl (Implen, Schatzbogen, Germany). 


\subsection{Molecular Cloning}

The ORF sequence of $C$. semilaevis Rspo3 was amplified using the TaKaRa Ex-Taq PCR kit and ligated to vector of pMD18-T (Takara). The template was mixed adult tissue cDNA, the pair of primers consisted of CS-Rspo3-ORF-Fw and CS-Rspo3-ORF-Rv (Table 1). The adult tissue was dissected from three one-year-old female fish (average weight is $145 \pm 10 \mathrm{~g}$ ) and three one-year-old male fish (average weight is $100 \pm 7 \mathrm{~g}$ ).

Table 1. Primers used in this study.

\begin{tabular}{|c|c|}
\hline Primer & Sequence $\left(5^{\prime}\right.$ to $\left.3^{\prime}\right)$ \\
\hline CS-Rspo3-ORF-Fw & TGGGCTACTATGCAATTACAACTG \\
\hline CS-Rspo3-ORF-Rv & AGAGGGAGCTCACTGTACAA \\
\hline CS-Rspo3-WISH-Fw & ATTTAGGTGACACTATAGAAGNGGGCACCGGCAACATAAAC \\
\hline CS-Rspo3-WISH-Rv & TAATACGACTCACTATAGGGAGACTCCACTCACCCACTTCAC \\
\hline CS-Rspo3-RT-PCR-Fw & GGGTCCTGTTGTGTTTAGGA \\
\hline CS-Rspo3-RT-PCR-Rv & TGCTGACCACCAGTGTAATC \\
\hline CS-Rspo3-mRNA-Fw & TAATACGACTCACTATAGGGAGAATGCAATTACAACTGATCTCCTTTG \\
\hline CS-Rspo3-mRNA-Rv & AGAGGGAGCTCACTGTACAA \\
\hline CS-Rspo3-ORF-EC-Fw & CGCGGATCCGCCACCATGCAATTACAACTGATCTCC \\
\hline CS-Rspo3-ORF-EC-Rv & CCGGAATTCGCTGTACAAGGTCATCATC \\
\hline CS-Rspo3-delFU1-Fw & CGGCAACATAAACAGATCATGCGCTCTCACGAAAGA \\
\hline CS-Rspo3-delFU1-Rv & TCTTTCGTGAGAGCGCATGATCTGTTTATGTTGCCG \\
\hline CS-Rspo3-delFU2-Fw & CCTCTGTGCGTCACTTTCGTGAGAGCGCATGC \\
\hline CS-Rspo3-delFU2-Rv & GCATGCGCTCTCACGAAAGTGACGCACCAGAGG \\
\hline CS-Rspo3-delFU3-Fw & GGTCCGCAGTGACGCAAACGACAAACTCATGG \\
\hline CS-Rspo3-delFU3-Rv & CCATGAGTTTGTCGTTTGCGTCACTGCGGACC \\
\hline CS-Rspo3-delTSP-Fw & CCACAAGTGCACTGTGAAGGACGGAGGAAGAATG \\
\hline CS-Rspo3-delTSP-Rv & САTТСТTССТССНТССТTСАСАGTGСАСТTGTGG \\
\hline B2M-RT-PCR-Fw & TGTTCGTCGTTC TGCCGTGT \\
\hline B2M-RT-PCR-Rv & TCAGGGTGTTGGGCTTGTTGT \\
\hline DR-VEGFa-RT-PCR-Fw & AGTTATTTCTCGCGGCTCTCC \\
\hline DR-VEGFa-RT-PCR-Rv & ACACATCCATGAAGGGAATCAC \\
\hline DR-ntl-RT-PCR-Fw & GGATGAAAGCACCCGTATC \\
\hline DR-ntl-RT-PCR-Rv & GTGTATCCTGGGTTCGTATTT \\
\hline DR-boz-RT-PCR-Fw & TAGAGACAGAGCAAGAGGAG \\
\hline DR-boz-RT-PCR-Rv & GGTGTCTCCTAAGATGTAATCAA \\
\hline DR-ZNRF3-RT-PCR-Fw & TTGGACCCAAGCTGTCTTAC \\
\hline DR-ZNRF3-RT-PCR-Rv & CACGCTGACCCTTGAACTTA \\
\hline DR-sp5l-RT-PCR-Fw & GGAGGTCACGTTGAGGATGG \\
\hline DR-sp5l-RT-PCR-Rv & GCGACAGCGACGAGTAGAGC \\
\hline DR- $\beta$-actin-RT-PCR-Fw & CCCAGACATCAGGGAGTGAT \\
\hline DR- $\beta$-actin-RT-PCR-Rv & TCTCTGTTGGCTTTGGATT \\
\hline DR-ntl-WISH-Fw & ATTTAGGTGACACTATAGAAGNGATGACTTCTTCCAACCCCG \\
\hline DR-ntl-WISH-Rv & TAATACGACTCACTATAGGGAGATCAGTAGCTCTGAGCCACAGG \\
\hline
\end{tabular}

\subsection{Phylogenetic Analysis}

Homologous amino acid sequences of Rspo3 were retrieved from NCBI (available online: http://www.ncbi.nlm.gov) and Ensemble (available online: www.ensembl.org). The sequences cover 35 species, including Homo sapiens (NP_116173.2), Mus musculus (NP_082627.3), Pan troglodytes (XP_001166327.1), Sus scrofa (NP_001302585.1), Orcinus orca (XP_004263897.1), Neomonachus schauinslandi (XP_021549174.1), Ornithorhynchus anatinus (XP_007656158.1), Gallus gallus (AGG55029.1), Columba livia (XP_005507484.1), Anas platyrhynchos (XP_005009653.1), Alligator mississippiensis (XP_006272521.2), Pygoscelis adeliae (XP_009323912.1), Pogona vitticeps (XP_020646342.1), Anolis carolinensis (XP_008120556.1), Python bivittatus (XP_007421067.1), Pelodiscus sinensis (XP_006139494.1), Alligator sinensis (XP_006027792.1), Chelonia mydas (XP_007064459.1), Xenopus tropicalis (NP_001123245.1), Rhincodon typus (XP_020372626.1), Callorhinchus milii (XP_007897453.1), 
Latimeria chalumnae (XP_006006810.1), Lipotes vexillifer (XP_007448028.1), Lepisosteus oculatus (XP_015205296.1), Danio rerio (NP_001017358.1), Takifugu rubripes (XP_003966018.1), Oryzias latipes (NP_001239178.1), Astyanax mexicanus (XP_007251874.1), Esox lucius (XP_012994802.1), Hippocampus comes (XP_019750648.1), Oreochromis niloticus (ENSONIP00000009097), Lates calcarifer (XP_018540154.1), Clupea harengus (XP_012692909.1), Paralichthys olivaceus (local data), and Cynoglossus semilaevis (local data). A phylogenetic tree was constructed by MrByes software (V.3.2.2), $\mathrm{mcmc}=200,000$ generations [49]. The protein domains were predicted by SMART (available online: http://smart. embl-heidelberg.de) and NCBI CD-search (available online: http:/ /www.ncbi.nlm.nih.gov/Structure/ cdd/wrpsb.cgi), and the schematic diagram was constructed by the online tool IBS (available online: http://ibs.biocuckoo.org/online.php).

\subsection{RT-PCR Analysis and WISH}

RT-PCR was employed to analyze the mRNA expression of different target genes and was executed using SYBR ${ }^{\circledR}$ Green I kit (Takara, Kagosima, Japan) on Roche Lightcycler 480. B2M was used as a reference gene in $C$. semilaevis, and $\beta$-actin was used as a reference gene in $D$. rerio. The primers containing "RT-PCR" in their names were used for RT-PCR (Table 1). The expression levels of different target genes were calculated using the 2- $\Delta \Delta C \mathrm{t}$ method. Each gene was amplified in triplicates, and the numeric data were presented as mean $\pm \mathrm{SD}$. Statistical significance was tested by one-way ANOVA using SPSS 20.0 (SPSS, Armonk, NY, USA) and was accepted when $p<0.05$.

WISH was carried out as described previously [50]. The sense and antisense mRNA probes of different target genes were synthesized with DIG RNA Labeling Mix (Indianapolis, IN, USA). Two pairs of primers (CS-Rspo3-WISH-Fw/Rv and DR-ntl-WISH-Fw/Rv) were used for probe synthesis (Table 1). The results were photographed by AZ100 (Nikon, Tokyo, Japan).

\section{6. mRNA Synthesis and Microinjection}

Capped mRNA of different target genes was synthesized with mMESSAGE mMACHINE@T7 (Ambion, Foster City, CA, USA). The primers were CS-Rspo3-mRNA-Fw and CS-Rspo3-mRNA-Rv (Table 1). Microinjection was carried out on Harvard Apparatus PLI-100 (NatureGene, NV, USA) machine in one- to four-cell-stage embryos with $1 \mathrm{nl}$ Rspo3 mRNA for each embryo. Embryos not injected were the control group.

\subsection{Luciferase Report Assay}

Luciferase report assays were performed with the Dual-Luciferase ${ }^{\circledR}$ Reporter Assay System (Promega, Madison, WI, USA), following the manufacturer's instructions. TOPFlash was used as a report plasmid, and Renilla was used as a reference plasmid. D. rerio embryos at one- to four-cell stage were injected with a mixture of target gene mRNA, TOPFlash plasmid, and Renilla plasmid, and raised until shield stage. Three independent samples (each with 30 embryos) of each group were lysed, and the ratio of firefly luciferase to Renilla luciferase was used as relative luciferase activity.

\subsection{Drug Treatment}

The activator BIO and the inhibitor XAV-939 were used to regulate the Wnt/ $\beta$-catenin signaling pathway. D. rerio embryos were incubated in corresponding solutions until phenotype observation and statistics or sampling for RNA extraction and WISH were performed.

\subsection{Mutant Plasmids Construction}

Wild-type $\left(\mathrm{P}^{\mathrm{RSPO}}\right.$ ) and mutant plasmids ( $\mathrm{P}^{\mathrm{RSPO} 3-d e l F U 1}, \mathrm{P}^{\mathrm{RSPO} 3-d e l F U}$ 2 $\mathrm{P}^{\mathrm{RSPO}}$-delFU3, $\mathrm{P}^{\mathrm{RSPO} 3-d e l T S P 1}$ ) were constructed to study the function of the protein domains. $\mathrm{P}^{\mathrm{RSPO} 3}$ was constructed by inserting C. semilaevis Rspo3 ORF sequence into PCS2+EGFP plasmid using EcoRI and BamHI restriction sites. The pair of primers was CS-Rspo3-ORF-EC-Fw and CS-Rspo3-ORF-EC-Rv (Table 1). The mutant plasmids were constructed by seamless cloning. Four pairs of primers (CS-Rspo3-delFU1-Fw / Rv, CS-Rspo3-delFU2-Fw/Rv, CS-Rspo3-delFU3-Fw/Rv, CS-Rspo3-delTSP1-Fw /Rv; Table 1) were designed 
by the online tool IDT (available online: https:/ /www.genomics.agilent.com/primerDesignProgram.jsp). Pfu DNA polymerase (ThermoFish Scientific, Shanghai, China) was used for PCR, and DpnI (NEB, Beijing, China) was used to digest the template plasmid.

Author Contributions: Conceptualization, J.N., J.Q., and Y.H.; Data curation, J.G., R.L., X.L., and Y.H.; Formal analysis, J.N.; Funding acquisition, J.Q. and Y.H.; Investigation, J.N., R.L., X.L., and J.Z.; Methodology, J.N., J.Z., J.Q., and Y.H.; Visualization, J.N.; Writing-original draft, J.N. and J.G.; Writing -review and editing, J.N., J.G., J.Q., and Y.H.

Funding: This research was funded by Fundamental Research Funds for the Central Universities (No. 201822026) and the National Natural Science Foundation of China (No. 31372511).

Acknowledgments: We thank Laizhou Mingbo Aquatic Co., Ltd., especially Wenhui Ma and Xiaomei Wang, for kindly providing the tongue sole samples.

Conflicts of Interest: We declare no conflict of interest. The funding sponsors had no role in the design of the study; in the collection, analyses, or interpretation of data; in the writing of the manuscript, and in the decision to publish the results.

\section{References}

1. Wang, W.; Yi, Q.; Ma, L.; Zhou, X.; Zhao, H.; Wang, X.; Qi, J.; Yu, H.; Wang, Z.; Zhang, Q. Sequencing and characterization of the transcriptome of half-smooth tongue sole (Cynoglossus semilaevis). BMC Genom. 2014, 15, 470. [CrossRef] [PubMed]

2. Chen, S.L.; Zhang, G.J.; Shao, C.W.; Huang, Q.F.; Liu, G.; Zhang, P.; Song, W.T.; An, N.; Chalopin, D.; Volff, J.N.; et al. Whole-genome sequence of a flatfish provides insights into ZW sex chromosome evolution and adaptation to a benthic lifestyle. Nat. Genet. 2014, 46, 253-260. [CrossRef] [PubMed]

3. De Lau, W.B.; Snel, B.; Clevers, H.C. The R-spondin protein family. Genome Biol. 2012, 13, 242. [CrossRef] [PubMed]

4. Kim, K.A.; Zhao, J.; Andarmani, S.; Kakitani, M.; Oshima, T.; Binnerts, M.E.; Abo, A.; Tomizuka, K.; Funk, W.D. R-Spondin proteins: A novel link to beta-catenin activation. Cell Cycle 2006, 5, 23-26. [CrossRef] [PubMed]

5. Rong, X.; Chen, C.; Zhou, P.; Zhou, Y.; Li, Y.; Lu, L.; Liu, Y.; Zhou, J.; Duan, C. R-spondin 3 regulates dorsoventral and anteroposterior patterning by antagonizing Wnt/beta-catenin signaling in zebrafish embryos. PLoS ONE 2014, 9, e99514. [CrossRef] [PubMed]

6. Kazanskaya, O.; Glinka, A.; Barrantes, I.D.; Stannek, P.; Niehrs, C.; Wu, W. R-spondin2 is a secreted activator of Wnt/beta-catenin signaling and is required for Xenopus myogenesis. Dev. Cell 2004, 7, 525-534. [CrossRef] [PubMed]

7. Kim, K.A.; Kakitani, M.; Zhao, J.; Oshima, T.; Tang, T.; Binnerts, M.; Liu, Y.; Boyle, B.; Park, E.; Emtage, P.; et al. Mitogenic influence of human R-spondin1 on the intestinal epithelium. Science 2005, 309, 1256-1259. [CrossRef] [PubMed]

8. Lowther, W.; Wiley, K.; Smith, G.H.; Callahan, R. A new common integration site, Int7, for the mouse mammary tumor virus in mouse mammary tumors identifies a gene whose product has furin-like and thrombospondin-like sequences. J. Virol. 2005, 79, 10093-10096. [CrossRef] [PubMed]

9. Kim, K.A.; Wagle, M.; Tran, K.; Zhan, X.M.; Dixon, M.A.; Liu, S.C.; Gros, D.; Korver, W.; Yonkovich, S.; Tomasevic, N.; et al. R-Spondin family members regulate the Wnt pathway by a common mechanism. Mol. Biol. Cell 2008, 19, 2588-2596. [CrossRef] [PubMed]

10. Chen, J.Z.; Wang, S.; Tang, R.; Yang, Q.S.; Zhao, E.P.; Chao, Y.Q.; Ying, K.; Xie, Y.; Mao, Y.M. Cloning and identification of a cDNA that encodes a novel human protein with thrombospondin type I repeat domain, hPWTSR. Mol. Biol. Rep. 2002, 29, 287-292. [CrossRef] [PubMed]

11. Aoki, M.; Mieda, M.; Ikeda, T.; Hamada, Y.; Nakamura, H.; Okamoto, H. R-spondin3 is required for mouse placental development. Dev. Biol. 2007, 301, 218-226. [CrossRef] [PubMed]

12. Nam, J.S.; Turcotte, T.J.; Smith, P.F.; Choi, S.; Yoon, J.K. Mouse cristin/R-spondin family proteins are novel ligands for the frizzled 8 and LRP6 receptors and activate beta-catenin-dependent gene expression. J. Biol. Chem. 2006, 281, 13247-13257. [CrossRef] [PubMed]

13. Nam, J.S.; Turcotte, T.J.; Yoon, J.K. Dynamic expression of R-spondin family genes in mouse development. Gene Expr. Patterns 2007, 7, 306-312. [CrossRef] [PubMed] 
14. Kazanskaya, O.; Ohkawara, B.; Heroult, M.; Wu, W.; Maltry, N.; Augustin, H.G.; Niehrs, C. The Wnt signaling regulator R-spondin 3 promotes angioblast and vascular development. Development 2008, 135, 3655-3664. [CrossRef] [PubMed]

15. Ohkawara, B.; Glinka, A.; Niehrs, C. Rspo3 binds Syndecan 4 and induces Wnt/PCP signaling via clathrin-mediated endocytosis to promote morphogenesis. Dev. Cell 2011, 20, 303-314. [CrossRef] [PubMed]

16. Aoki, M.; Kiyonari, H.; Nakamura, H.; Okamoto, H. R-spondin2 expression in the apical ectodermal ridge is essential for outgrowth and patterning in mouse limb development. Dev. Growth Differ. 2008, 50, 85-95. [CrossRef] [PubMed]

17. Da Silva, F.; Rocha, A.S.; Motamedi, F.J.; Massa, F.; Basboga, C.; Morrison, H.; Wagner, K.D.; Schedl, A. Coronary artery formation is driven by localized expression of R-spondin3. Cell Rep. 2017, 20, 1745-1754. [CrossRef] [PubMed]

18. Kannan, L.; Kis-Toth, K.; Yoshiya, K.; Thai, T.H.; Sehrawat, S.; Mayadas, T.N.; Lucca, J.J.D.; Tsokos, G.C. R-spondin3 prevents mesenteric ischemia/reperfusion-induced tissue damage by tightening endothelium and preventing vascular leakage. Proc. Natl. Acad. Sci. USA 2013, 110, 14348-14353. [CrossRef] [PubMed]

19. Cambier, L.; Plate, M.; Sucov, H.M.; Pashmforoush, M. Nkx2-5 regulates cardiac growth through modulation of Wnt signaling by R-spondin3. Development 2014, 141, 2959-2971. [CrossRef] [PubMed]

20. Neufeld, S.; Rosin, J.M.; Ambasta, A.; Hui, K.; Shaneman, V.; Crowder, R.; Vickerman, L.; Cobb, J. A conditional allele of Rspo3 reveals redundant function of R-spondins during mouse limb development. Genesis 2012, 50, 741-749. [CrossRef] [PubMed]

21. Rocha, A.S.; Vidal, V.; Mertz, M.; Kendall, T.J.; Charlet, A.; Okamoto, H.; Schedl, A. The angiocrine factor Rspondin3 is a key determinant of liver zonation. Cell Rep. 2015, 13, 1757-1764. [CrossRef] [PubMed]

22. Theodorou, V.; Kimm, M.A.; Boer, M.; Wessels, L.; Theelen, W.; Jonkers, J.; Hilkens, J. MMTV insertional mutagenesis identifies genes, gene families and pathways involved in mammary cancer. Nat. Genet. 2007, 39, 759-769. [CrossRef] [PubMed]

23. Galetzka, D.; Hansmann, T.; El Hajj, N.; Weis, E.; Irmscher, B.; Ludwig, M.; Schneider-Ratzke, B.; Kohlschmidt, N.; Beyer, V.; Bartsch, O.; et al. Monozygotic twins discordant for constitutive BRCA1 promoter methylation, childhood cancer and secondary cancer. Epigenetics 2012, 7, 47-54. [CrossRef] [PubMed]

24. Seshagiri, S.; Stawiski, E.W.; Durinck, S.; Modrusan, Z.; Storm, E.E.; Conboy, C.B.; Chaudhuri, S.; Guan, Y.H.; Janakiraman, V.; Jaiswal, B.S.; et al. Recurrent R-spondin fusions in colon cancer. Nature 2012, 488, 660-664. [CrossRef] [PubMed]

25. Han, T.; Schatoff, E.M.; Murphy, C.; Zafra, M.P.; Wilkinson, J.E.; Elemento, O.; Dow, L.E. R-Spondin chromosome rearrangements drive Wnt-dependent tumour initiation and maintenance in the intestine. Nat. Commun. 2017, 8, 1-12. [CrossRef] [PubMed]

26. Duncan, E.L.; Danoy, P.; Kemp, J.P.; Leo, P.J.; McCloskey, E.; Nicholson, G.C.; Eastell, R.; Prince, R.L.; Eisman, J.A.; Jones, G.; et al. Genome-wide association study using extreme truncate selection identifies novel genes affecting bone mineral density and fracture risk. PLoS Genet. 2011, 7, e1001372. [CrossRef] [PubMed]

27. Hsu, Y.H.; Kiel, D.P. Genome-wide association studies of skeletal phenotypes: What we have learned and where we are headed. J. Clin. Endocr. Metab. 2012, 97, E1958-E1977. [CrossRef] [PubMed]

28. Moayyeri, A.; Hsu, Y.H.; Karasik, D.; Estrada, K.; Xiao, S.M.; Nielson, C.; Srikanth, P.; Giroux, S.; Wilson, S.G.; Zheng, H.F.; et al. Genetic determinants of heel bone properties: Genome-wide association meta-analysis and replication in the GEFOS/GENOMOS consortium. Hum. Mol. Genet. 2014, 23, 3054-3068. [CrossRef] [PubMed]

29. Heid, I.M.; Jackson, A.U.; Randall, J.C.; Winkler, T.W.; Qi, L.; Steinthorsdottir, V.; Thorleifsson, G.; Zillikens, M.C.; Speliotes, E.K.; Magi, R.; et al. Magic, Meta-analysis identifies 13 new loci associated with waist-hip ratio and reveals sexual dimorphism in the genetic basis of fat distribution. Nat. Genet. 2010, 42, 949-960. [CrossRef] [PubMed]

30. Kim, Y.J.; Go, M.J.; Hu, C.; Hong, C.B.; Kim, Y.K.; Lee, J.Y.; Hwang, J.Y.; Oh, J.H.; Kim, D.J.; Kim, N.H.; et al. Large-scale genome-wide association studies in east Asians identify new genetic loci influencing metabolic traits. Nat. Genet. 2011, 43, 990-995. [CrossRef] [PubMed]

31. Liu, C.T.; Monda, K.L.; Taylor, K.C.; Lange, L.; Demerath, E.W.; Palmas, W.; Wojczynski, M.K.; Ellis, J.C.; Vitolins, M.Z.; Liu, S.M.; et al. Genome-wide association of body fat distribution in African ancestry populations suggests new loci. PLoS Genet. 2013, 9, e1003681. [CrossRef] [PubMed] 
32. Kim, H.; Ryu, J.; Lee, C. Genome-wide identification of expression quantitative trait loci for human telomerase. Medicine 2016, 95, e5209. [CrossRef] [PubMed]

33. Schier, A.F.; Talbot, W.S. Molecular genetics of axis formation in zebrafish. Annu. Rev. Genet. 2005, 39, 561-613. [CrossRef] [PubMed]

34. Kimmel, C.B.; Ballard, W.W.; Kimmel, S.R.; Ullmann, B.; Schilling, T.F. Stages of embryonic-development of the zebrafish. Dev. Dyn. 1995, 203, 253-310. [CrossRef] [PubMed]

35. Huber, T.L.; Kouskoff, V.; Fehling, H.J.; Palis, J.; Keller, G. Haemangioblast commitment is initiated in the primitive streak of the mouse embryo. Nature 2004, 432, 625-630. [CrossRef] [PubMed]

36. Binnerts, M.E.; Kim, K.A.; Bright, J.M.; Patel, S.M.; Tran, K.; Zhou, M.; Leung, J.M.; Liu, Y.; Lomas, W.E.; Dixon, M.; et al. R-Spondin1 regulates Wnt signaling by inhibiting internalization of LRP6. Proc. Natl. Acad. Sci. USA 2007, 104, 14700-14705. [CrossRef] [PubMed]

37. Glinka, A.; Dolde, C.; Kirsch, N.; Huang, Y.L.; Kazanskaya, O.; Ingelfinger, D.; Boutros, M.; Cruciat, C.M.; Niehrs, C. LGR4 and LGR5 are R-spondin receptors mediating Wnt/beta-catenin and Wnt/PCP signalling. Embo Rep. 2011, 12, 1055-1061. [CrossRef] [PubMed]

38. Langdon, Y.G.; Mullins, M.C. Maternal and zygotic control of zebrafish dorsoventral axial patterning. Annu. Rev. Genet. 2011, 45, 357-377. [CrossRef] [PubMed]

39. Carmon, K.S.; Gong, X.; Lin, Q.S.; Thomas, A.; Liu, Q.Y. R-spondins function as ligands of the orphan receptors LGR4 and LGR5 to regulate Wnt/beta-catenin signaling. Proc. Natl. Acad. Sci. USA 2011, 108, 11452-11457. [CrossRef] [PubMed]

40. De Lau, W.; Barker, N.; Low, T.Y.; Koo, B.K.; Li, V.S.W.; Teunissen, H.; Kujala, P.; Haegebarth, A.; Peters, P.J.; van de Wetering, M.; et al. Lgr5 homologues associate with Wnt receptors and mediate R-spondin signalling. Nature 2011, 476, 293-297. [CrossRef] [PubMed]

41. Hao, H.X.; Xie, Y.; Zhang, Y.; Charlat, O.; Oster, E.; Avello, M.; Lei, H.; Mickanin, C.; Liu, D.; Ruffner, H.; et al. ZNRF3 promotes Wnt receptor turnover in an R-spondin-sensitive manner. Nature 2012, 485, 195-200. [CrossRef] [PubMed]

42. Koo, B.K.; Spit, M.; Jordens, I.; Low, T.Y.; Stange, D.E.; van de Wetering, M.; van Es, J.H.; Mohammed, S.; Heck, A.J.R.; Maurice, M.M.; et al. Tumour suppressor RNF43 is a stem-cell E3 ligase that induces endocytosis of Wnt receptors. Nature 2012, 488, 665-669. [CrossRef] [PubMed]

43. Carmon, K.S.; Lin, Q.S.; Gong, X.; Thomas, A.; Liu, Q.Y. LGR5 Interacts and cointernalizes with Wnt receptors to modulate Wnt/beta-catenin signaling. Mol. Cell. Biol. 2012, 32, 2054-2064. [CrossRef] [PubMed]

44. Ruffner, H.; Sprunger, J.; Charlat, O.; Leighton-Davies, J.; Grosshans, B.; Salathe, A.; Zietzling, S.; Beck, V.; Therier, M.; Isken, A.; et al. R-Spondin potentiates Wnt/beta-catenin signaling through orphan receptors LGR4 and LGR5. PLoS ONE 2012, 7, e40976. [CrossRef] [PubMed]

45. Chen, P.H.; Chen, X.Y.; Lin, Z.H.; Fang, D.Y.; He, X.L. The structural basis of R-spondin recognition by LGR5 and RNF43. Gene Dev. 2013, 27, 1345-1350. [CrossRef] [PubMed]

46. Lebensohn, A.M.; Rohatgi, R. R-spondins can potentiate WNT signaling without LGRs. eLife 2018, 7, e33126. [CrossRef] [PubMed]

47. Zebisch, M.; Jones, E.Y. Crystal structure of R-spondin 2 in complex with the ectodomains of its receptors LGR5 and ZNRF3. J. Struct. Biol. 2015, 191, 149-155. [CrossRef] [PubMed]

48. Zebisch, M.; Xu, Y.; Krastev, C.; MacDonald, B.T.; Chen, M.R.; Gilbert, R.J.C.; He, X.; Jones, E.Y. Structural and molecular basis of ZNRF3/RNF43 transmembrane ubiquitin ligase inhibition by the Wnt agonist R-spondin. Nat. Commun. 2013, 4, 2787. [CrossRef] [PubMed]

49. Ronquist, F.; Teslenko, M.; van der Mark, P.; Ayres, D.L.; Darling, A.; Hohna, S.; Larget, B.; Liu, L.; Suchard, M.A.; Huelsenbeck, J.P. MrBayes 3.2: Efficient Bayesian phylogenetic inference and model choice across a large model space. Syst. Biol. 2012, 61, 539-542. [CrossRef] [PubMed]

50. Liu, J.X.; Liu, T.T.; Niu, J.J.; Wu, X.L.; Zhai, J.M.; Zhang, Q.Q.; Qi, J. Expression pattern and functional analysis of R-spondin1 in tongue sole Cynoglossus semilaevis. Gene 2018, 642, 453-460. [CrossRef] [PubMed]

(C) 2018 by the authors. Licensee MDPI, Basel, Switzerland. This article is an open access article distributed under the terms and conditions of the Creative Commons Attribution (CC BY) license (http:/ / creativecommons.org/licenses/by/4.0/). 